\title{
Necrotizing Fasciitis of the Anterior Abdominal Wall: A Rare Complication of Neglected Strangulated
} Richter's Epigastric Hernia

\author{
Anwar Sadat Seidu ${ }^{1,2}$, Edwin M.T. Yenli ${ }^{1,2}$, Martin Kyereh ${ }^{1,2}$, David P. Suoseg ${ }^{3}$, Musah Yakubu ${ }^{1}$, Bernard N. \\ Maanikuu ${ }^{1}$, Gerald Batariwah ${ }^{1}$, Emmanuel A. N. Azure ${ }^{1}$, Imoro Osman ${ }^{1}$, Haruna Danamiji Osman ${ }^{1}$, Abdul-Latif \\ Alhassan ${ }^{1}$, Abdul Aziz Ewura ${ }^{1}$, John F. Busuuri ${ }^{1}$ \\ ${ }^{1}$ Department of Surgery, Tamale Teaching Hospital, Box TL 16, Tamale, Ghana. \\ ${ }^{2}$ Department of Surgery; School of Medicine and Health Sciences, University for Development Studies, Box TL \\ 1350, Tamale, Ghana. \\ ${ }^{3}$ Department of Obstetrics and Gynecology, Tamale Teaching Hospital, Box TL 16, Tamale, Ghana.
}

Corresponding author: Anwar Sadat Seidu; anwarseidu@gmail.com

Received: 24 November 2020;

Accepted: 10 December 2020;

Published: 12 December 2020

\begin{abstract}
Necrotizing soft tissue infection (NSTI) is an aggressive and rapidly spreading soft tissue infection that could be associated with high mortality. Early diagnosis can be challenging and so a high index of suspicion is needed. Bedside ultrasonography (USG) and computed tomography (CT) scan could be employed to aid in diagnosis. The objective of this report is to describe the diagnostic process in a resource challenged setting and review the literature. We present an elderly patient with necrotizing fasciitis of the anterior abdominal wall as a complication of neglected strangulated Richter's epigastric hernia that resulted in mortality.
\end{abstract}

Keywords: necrotizing fasciitis, epigastric hernia, LRINEC score, neglected.

\section{Introduction}

Necrotizing fasciitis is a fatal and rapidly spreading soft tissue infection ${ }^{[1-3]}$. Common causes include postoperative wound infection, trauma, strangulated hernia and perianal abscess ${ }^{[2,4]}$. It is commonly caused by aerobes (gram negatives and positives) and anaerobes. The majority of cases are caused by polymicrobial organisms ${ }^{[2,5]}$. Necrotizing soft tissue infection (NSTI) is associated with high mortality rate of $25-76 \%{ }^{[2,6,7]}$. Early diagnosis can pose diagnostic dilemma to the clinician but is crucial for survival ${ }^{[2,5]}$. A high index of suspicion is therefore needed. Wong et al (2004) devised the laboratory risk indicator for necrotizing fasciitis (LRINEC) score which is a useful clinical tool for early diagnosis of NSTI ${ }^{[8]}$. NSTI is investigated using bedside ultrasonography (USG) and computed tomography (CT) scan ${ }^{[6,9,10]}$. Early wound debridement is the recommended treatment and it improves survival ${ }^{[3,5,7]}$.

We report an elderly patient with a necrotizing fasciitis of the anterior abdominal wall as a complication of neglected strangulated Richter's epigastric hernia involving the transverse colon. We illustrate the diagnostic process in a low resource setting and review of literature.

\section{Case Presentation}

A 78- year old male who has had an epigastric lump for 30-years. The lump increased anytime he coughed or bears down and reduced spontaneously. This did not bother him except for little epigastric discomfort. Three weeks prior to presentation the lump became irreducible and he began to experience colicky abdominal pain that became constant. This was associated with fever, nausea, vomiting, but no abdominal distention, constipation, or unintended weight loss. Over a 3-week's period, the pain got worse and he noticed a gradual swelling of the anterior abdominal wall and a change in color of the skin.

He had no history of hypertension, diabetes mellitus, hyperlipidemia, retroviral infection, or inflammatory bowel disease. His family history was insignificant. He resorted to herbal medications (both oral and topical), but with no improvement of his condition. He reported to a primary care facility where he was immediately referred to Tamale Teaching Hospital.

On examination, he was an elderly man with temperature $36.00 \mathrm{C}$, pulse rate $113 \mathrm{bpm}$, blood pressure $88 / 55 \mathrm{mmHg}$ and respiratory rate $24 \mathrm{cpm}$. He had conjunctival pallor, anicteric and was moderately dehydrated. Heart sounds were normal with no 
murmurs. On abdominal examination, he had a discolored swelling of the anterior abdominal wall which measured $43 \times 35 \mathrm{~cm}$ extending from the right upper quadrant to the right lower quadrant, across the midline and into the left upper and lower quadrant. The skin of the abdominal wall was dark and necrotic. The necrotic portion had a fluctuant bump that was non-tender. The rest of the abdominal wall was tender with no established peritonism but had crepitations on palpation. Bowel sounds were present and normal. Rectal examination was unremarkable.

\section{Laboratory and Radiological Imaging}

Baseline laboratory results were as follows: total white blood cell count $(\mathrm{WBC})=26 \times 109 / \mathrm{L} \uparrow \uparrow$, hemoglobin $=10.3 \mathrm{~g} / \mathrm{dl} \downarrow$, creatinine $=151 \mathrm{umol} / \mathrm{L} \uparrow$, sodium $=145 \mathrm{mmol} / \mathrm{L} \leftrightarrow$, random blood glucose $=6.8 \mathrm{mmol} / \mathrm{L} \leftrightarrow$ and C-reactive protein $(\mathrm{CRP})=158 \mathrm{mg} / \mathrm{L}$ $\uparrow$. The LRINEC score was 12 based on these laboratory findings. There were no electrolyte abnormalities.

Abdominopelvic ultrasound showed edematous and thickened subcutaneous tissue, air, and distorted fascial planes with accumulation of turbid fluid. The liver, spleen, kidneys, and the peritoneal cavity were normal. Abdominal X-rays showed soft tissue gas. Abdominopelvic CT scan was not done because patient could not afford it.

A diagnosis of necrotizing fasciitis of anterior abdominal wall was made and patient was counselled for urgent wound debridement. He was started on broad spectrum antibiotics and optimized for surgery. Urine output was adequate prior to surgery.

Extensive debridement of skin, subcutaneous tissue and fascia was performed under general anesthesia. Intraoperative findings were dark necrotic skin of two thirds of the anterior abdominal wall. The fascial planes were thickened and destroyed in most parts. Within this plane was copious collection of fecal matter. There was midline epigastric fascial defect $(2.5 \times 2 \mathrm{~cm})$, about $6 \mathrm{~cm}$ from xiphisternum. In the defect was a portion of the circumference of the transverse colon that had perforated $(2 \times 1 \mathrm{~cm})$ and had necrotic edges (Richter's type hernia). The omentum had formed a barrier to seal off the peritoneal cavity. Extensive debridement was performed and drainage of about $2 \mathrm{~L}$ of fecal matter from the abdominal wall. After debridement, a controlled wound irrigation with saline prevent peritoneal contamination was performed. The surgical team rescrubbed and gowned and then performed an open laparotomy to explore the peritoneal cavity. The transverse colon was isolated and a transverse colectomy with end to end anastomosis was performed. The other peritoneal viscera were normal and there was no peritoneal soiling. Fascia was closed and epigastric defect repaired. Intraoperatively, the patient's blood pressure was sustained with inotropes. The patient had cardiac arrest on the table and despite appropriate resuscitative measures, he died. His family declined our request for autopsy.
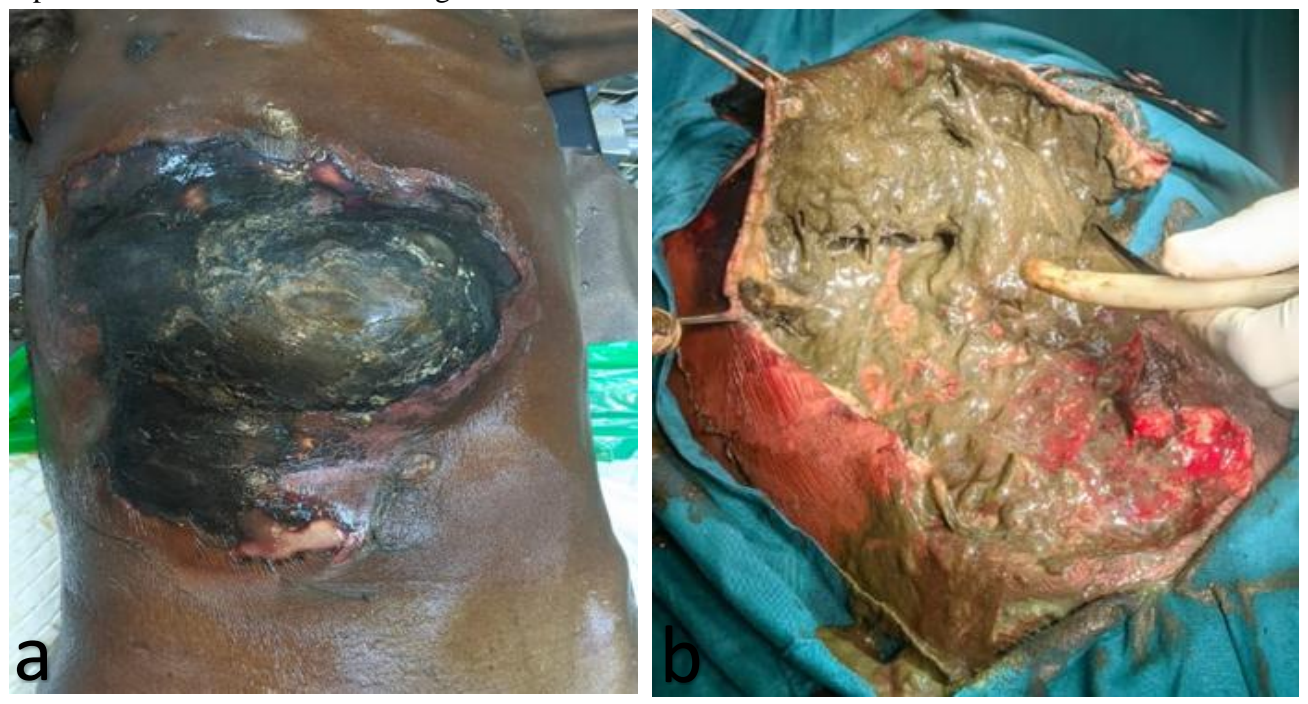

Figure 1: a) Necrotizing soft tissue infection of anterior abdominal wall, b) Surgical debridement of necrotic tissue showing fecal content.
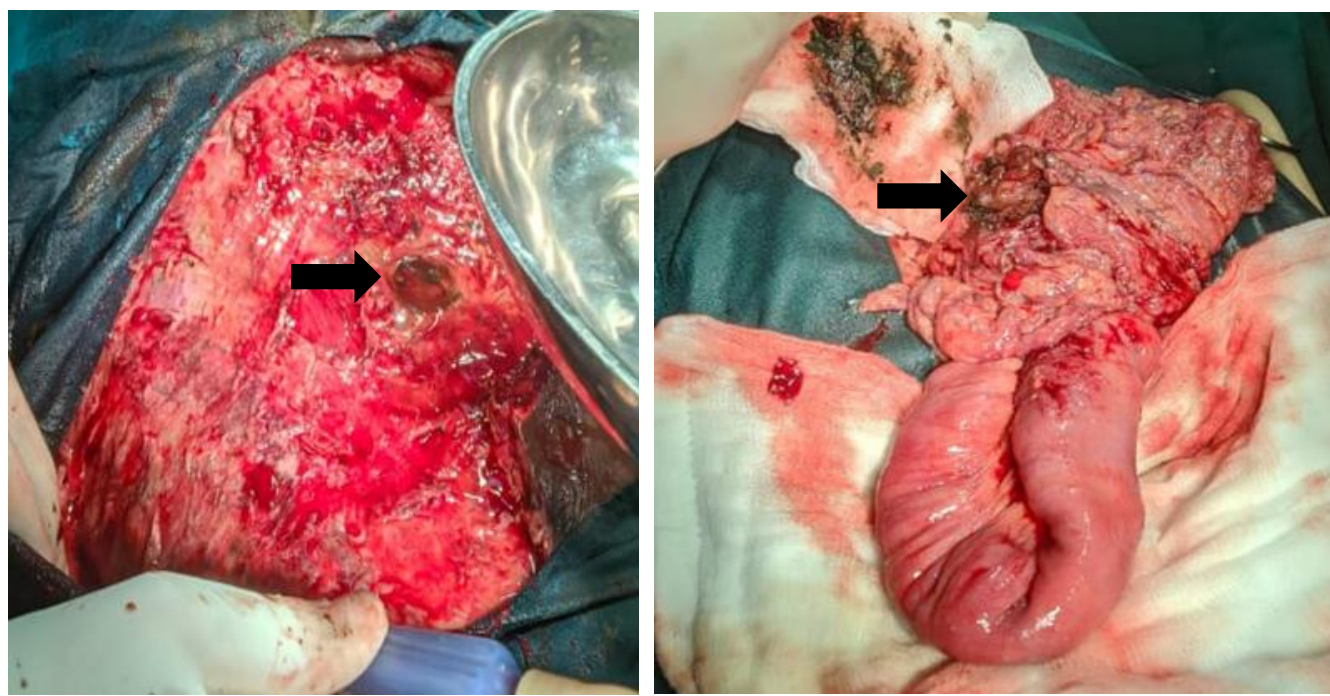

Figure 2: a) Wound after debridement showing fascial defect in epigastrium (arrow), b) Perforated transverse colon (arrow). 


\section{Discussion}

Necrotizing fasciitis is a fatal soft tissue infection and for that reason a high index of suspicion is required to make an early diagnosis ${ }^{[2,3,7,11]}$. Postoperative wound complications and trauma account for more than $50 \%$ of cases of NSTI ${ }^{[2]}$. Strangulated hernia is not a common cause of NSTI $(3.1 \%)^{[2]}$. In this case report, the patient is an elderly man who presented 3-weeks after a strangulated epigastric hernia. The window of opportunity for surgical intervention was missed because he presented late.

Wong et al (2004) devised the LRINEC score which is a useful diagnostic tool for early clinical diagnosis of NSTI ${ }^{[8,12]}$. It is capable of distinguishing necrotizing infections from nonnecrotizing infections. The score is based on six laboratory parameters (WBC, hemoglobin, creatinine, sodium, glucose, and CRP). The total score is associated with a low risk $(\leq 5)$, intermediate risk (6-7) and high risk $(\geq 8)$ of NSTI ${ }^{[8]}$. The patient had a LRINEC score of 12 which is associated with a high risk and $75 \%$ probability of NSTI ${ }^{[8,12]}$.

NSTI is evaluated using bedside USG and CT scan ${ }^{[6,9,10]}$. Castleberg et al (2013) described the use of bedside USG for rapid diagnosis of unstable patients ${ }^{[9]}$. They proposed the use of the STAFF exam (subcutaneous thickening, air and fascial fluid) [9]. In this case, the STAFF exam was employed for rapid diagnosis of the patient. Bedside USG showed edematous and thickened subcutaneous tissue, air, and distorted fascial planes with fluid accumulation. However, the underlying cause of the necrotizing fasciitis could not be ascertained with USG. CT scan is the most sensitive of the imaging modalities for NSTI ${ }^{[6,10]}$. A positive or negative helical CT finding reliably confirms or excludes NSTI ${ }^{[6]}$. In this case, CT scan could have identified the underlying epigastric hernia prior to surgical intervention. However, this was not done because the patient could not afford it. This would have aided the surgical team to plan appropriately.

The principles of management of NSTI include infection source control, antibiotic therapy, physiologic support and monitoring ${ }^{[4]}$. Early extensive surgical debridement is crucial for survival ${ }^{[3,5,7,13]}$. A multidisciplinary approach is required to achieve optimal care ${ }^{[4]}$. In this case, the late presentation contributed to the catastrophic outcome of the patient. Extensive surgical debridement was done with the required physiologic support. Patient succumbed to septic shock and died of cardiac arrest on table.

\section{Conclusion}

Early NSTI pose diagnostic dilemma to the clinician and so a high index of suspicion is needed. It is associated with a high mortality rate when presentation is late. Early surgical debridement averts catastrophic outcomes.

\section{Consent}

An informed consent was taken from the patient's family for the publication of this case report and its related pictures.

\section{List of Abbreviations}

NSTI: Necrotizing soft tissue infection,

USG: Ultrasonography

CT: Computed Tomography

STAFF exam: Subcutaneous Thickness, Air, Fascial Fluid
LRINEC score: Laboratory risk indicator for necrotizing fasciitis

WBC: White Blood Cell

CRP: C-Reactive Protein

\section{Conflict of interest}

All authors declared no conflict of interest with respect to publication of this paper.

\section{Funding Statement}

Authors did not receive funding for this paper.

\section{Authors' contribution}

ASS conceived the idea, ASS and EMTY drafted the manuscript, all wrote case summary. ASS and GB performed surgery. EMTY and MKK supervised the manuscript. All authors critically reviewed the manuscript for academic readership.

\section{References}

[1] Roje Z, Roje Ž, Matić D, Librenjak D, Dokuzović S, Varvodić J. Necrotizing fasciitis: literature review of contemporary strategies for diagnosing and management with three case reports: torso, abdominal wall, upper and lower limbs. World J Emerg Surg. 2011 Dec 23;6(1):46.

[2] McHenry CR, Piotrowski JJ, Petrinic D, Malangoni MA. Determinants of mortality for necrotizing soft-tissue infections. Ann Surg. 1995 May;221(5):558-65.

[3] Morgan MS. Diagnosis and management of necrotising fasciitis: a multiparametric approach. J Hosp Infect. 2010 Aug 1;75(4):249-57.

[4] Townsend Jr CM, Beauchamp RD. Sabiston Textbook of Surgery: The Biological Basis of Modern Surgical Practice, 19th Edition. 19th ed. Elsevier; 2008.

[5] Goldstein EJC, Anaya DA, Dellinger EP. Necrotizing Soft-Tissue Infection: Diagnosis and Management. Clin Infect Dis. 2007 Mar 1;44(5):705-10.

[6] Zacharias N. Diagnosis of Necrotizing Soft Tissue Infections by Computed Tomography. Arch Surg. 2010 May 1;145(5):452.

[7] Green RJ, Dafoe DC, Rajfin TA. Necrotizing Fasciitis. Chest. 1996 Jul 1;110[ 1]:219-29.

[8] Wong C-H, Khin L-W, Heng K-S, Tan K-C, Low C-O. The LRINEC (Laboratory Risk Indicator for Necrotizing Fasciitis) score: a tool for distinguishing necrotizing fasciitis from other soft tissue infections. Crit Care Med. 2004 Jul;32(7):1535-41.

[9] Castleberg E, Jenson N, Dinh VA. Diagnosis of Necrotizing Faciitis with Bedside Ultrasound: the STAFF Exam. West J Emerg Med. 2014 Feb;15(1):1113.

[10] Wysoki MG, Santora TA, Shah RM, Friedman AC. Necrotizing fasciitis: CT characteristics. Radiology. 1997 Jun 1;203(3):859-63.

[11] Stamenkovic I, Lew PD. Early Recognition of Potentially Fatal Necrotizing Fasciitis: The Use of Frozen-Section Biopsy. N Engl J Med. 1984 Jun 28;310(26):1689-93.

[12] Bechar J, Sepehripour S, Hardwicke J, Filobbos G. Laboratory risk indicator for necrotising fasciitis (LRINEC) score for the assessment of early necrotising 
fasciitis: a systematic review of the literature. Ann R Coll Surg Engl. 2017 May;99(5):341-6.

[13] Voros D, Pissiotis C, Georgantas D, Katsaragakis S, Antoniou S, Papadimitriou J. Role of early and extensive surgery in the treatment of severe necrotizing soft tissue infection. BJS Br J Surg. 1993;80(9):1190-1. 